\title{
Childhood Neurotic Traits
}

\section{Shakya DN ${ }^{1}$}

${ }^{1}$ Dr Dhana Ratna Shakya. MBBS. MD Dept of Psychiatry, BP Kirala Institute of Health Sciences, Dharan.

Address for correspondence: E-mail Address: drdhanashakya@yahoo.com

\section{Introduction:}

'Child is the father of a man.' As Wordsworth has rightly said, the behavior and nature of a man is largely the continuation of them over the life span though there is some variation in the degree. So, the psychiatric assessment of a person is never complete without assessment of childhood neurotic traits. Even though there is tendency to omit the personal history (including childhood neurotic traits) in busy settings like the OPD, the presenting problem at times may be related to childhood neurotic traits in one or other way. Here, an attempt will be made to review the literature regarding 'childhood neurotic traits'.

While talking about childhood neurotic traits, three basic concepts should be kept in mind: child development, neuroticism and traits. Human being undergoes different stages of development in respect to various functions (cognitive, social, psychosexual, etc.). During early childhood, children develop the capacity to respond to anxiety provoking situation by different defense mechanisms. Many children develop maladaptive behaviors or patterns. Some of the age appropriate mental problems are expressed by the appearance of regressive behaviors and fears. They are referred to as 'childhood neurotic traits'.

As the terms, 'personality', 'traits' and 'temperament' are closely related and at times confusing, they have been elaborated here.

Personality: Personality is the overall quality within a person or characteristics of a person's behavior or the both. Gordon Allport (1937) defines it as 'Dynamic organization within individual of those psychophysical systems that determine his/her unique adjustment to his/her environment'. Walter Mischel (1976) emphasized more on the 'distinctive patterns of behavior (including thoughts and emotions) that characterizes each individual's adaptation to the situations of his/ her life'.

Personality has been studied in a number of different ways, type and trait approach is one of the popular personality theories (others being dynamic, learning, behavioral and humanistic approach). Type and trait approach of personality focuses on people's personal characteristics. Trait theories of personality try to describe it in terms of traits.

Traits: Traits are characteristics that lead people to behave in more or less distinctive and consistent ways across situations. It is the product of learning based on a hereditary foundation. Gordon Allport has defined three types of traits:
1. Cardinal traits: Dominant traits that nearly all of the individual's actions can be traced back to them, e.g. Ram like.

2. Central traits: Though most people do not display cardinal traits, their behavior is characterized by some traits to some extent (not as complete as by cardinal traits).

3. Secondary traits: Traits that are influential only within a narrow range of situations, e.g. likes chocolates.

Temperament: Temperament is that aspect of the personality which includes mood, activity level, emotion and the variability of each of them. Twin human studies show a great genetic influence (in studies involving mother rating their children on 4 dimensions- emotionality, activity, sociability and impulsivity).

Trait Development: Child learns by imitating a person whom he /she identified him/herself with; trial and error, and by chances. The core of the pattern is the self-concept that remains fundamentally the same. Once self-concept is fixed, it does not change unless radical steps are taken to produce a change. In young children, the core of personality is not well established. It therefore can be changed without disturbing the total personality balance.

\section{Childhood Neurotic Traits:}

Some of the so-called childhood neurotic traits include the following:

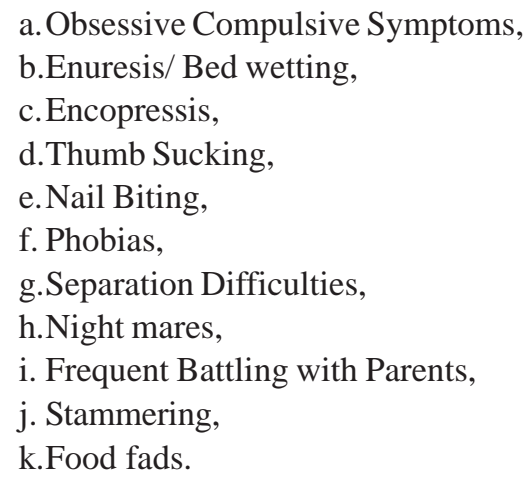

Development Of Childhood Neurotic Traits: Freud and Rank have stressed the importance of early life experiences. There is now ample evidence that the attitude, behavior and emotional reactions of patterns and the total cultural context of environment in which child grows up, are of great importance in determining the pattern of personality. Freud maintained that neurotic traits are based on unconscious conflicts. It applies also to childhood neurotic traits. 
The powerful wish to get rid of the same sex parents and to assume his/her role in an exclusive, intimate relationship with the opposite sex parents is also fought with tension as the child struggles with love and hate felt towards the rival. The experience of hurt, tension and uncertainty during Oedipal phase (4-6 years) leads to the development of internalized conflicts. The child has now the capacity for neurosis i.e. an internal struggle between opposing forces (wishes versus personal values or desires versus parental attitudes and opposing desires). The infantile neurosis is a form of age appropriate mental disorders/ problems engaged by Oedipal phase constructs/ structures.

It is expressed by the appearance of regressive behaviors and fears. These are quite common in the period of development and serve the child's development by attempts to withdraw from or displace the conflicts aroused by the intensity of his or her Oedipal longings.

\section{Implications in Paediatric Psychiatry:}

Baley, Busk Cattell, Macroft and others have studied children over periods of time and have emphasized the persistence of personality pattern in recent years. Glueck showed-problem children grow up into problem adolescents and adults. Glavin studied the maladjusted people and found that the unusual behavior in childhood is often a precursor of personality disturbances in adulthood. The relationship between behaviors in children and neurotic illness in adult life has been reviewed by Rutter (1972). He concluded that although there was some continuity between child and adult neurosis, most neurotic children become normal adults and most neurotic adults develop their neurosis in adult life.

Most of the evidence of a positive relationship comes from retrospective assessments of adult neurotic populations, and even when these are compared with carefully matched controls, the possibility of retrospective distortion makes firm conclusions difficult to draw.

Robins (1966) followed up a group of 5000 psychiatric patients for 30 years period and compared them with a matched control group of 100 normal children. She found that most of the children who were referred for neurotic problems did not suffer from neurosis as adult and that those adults who did show neurotic symptoms were just as likely to have been in the control group as children as in child psychiatric clinic group.

Mellshop (1972) followed up a group of 3000 children who had presented to an Australian child psychiatric clinic 20 years earlier. He found that child psychiatric patients were 3 times as likely as controls to receive psychiatric treatments as adult but that there was little correlation between particular symptom patterns in childhood and adult life.

One interesting and consistent finding is that - whereas in adults there is a preponderance of females with neurosis, there is an excess of boys in children. This change in sex distribution takes place during adolescence. Its significance is not clear. It may be that adult female neurotics are more likely to seek help and accept treatment from doctors than their male counterparts, or that neurotic symptoms evaporate during adolescence in males, or that males cope with stress and anxieties with different behaviors such as alcohol and drug abuse in adult life.

The childhood neurotic traits seem to have little association with earlier childhood or adult neurosis. These all are quite common phenomena and are usually not indicative of maladjustment or psychiatric disorders. So far, only relationship between children and adult neurosis has been considered. In the study of Goodwin et al (2003) involving 1265 patients with psychotic symptoms in adulthood, they were found to have 2-3 times more neuroticism in adolescence than normal (may be precursor with unknown mechanism). Very little is known about other childhood behaviors or personality traits in children that may be associated with child neurosis. There is a need for prospective developmental studies continuing into adult life.

\section{Approach to a Child with Neurotic Traits:}

\section{Assessment:}

If syndromal diagnosis (persistent, pervasive, problematic and associated with symptoms of known psychiatric disorder): manage accordingly.

If only at symptom or trait level: follow up for monitoring.

2. Psycho-Education: To significant care providers (parents) regarding-

A. The age appropriateness of the problem,

B. Their roles as a responsible parent: (Care, love, discipline, safety/security, honesty, play).

a) Carefully observe the things that provoke these behaviors, e.g. thumb sucking,

b) Find ways of avoiding these trigger factors,

c) Provide extra attention,

d) Organize pleasant distractions,

e) Give praise and rewards for the efforts to stop.

C. To avoid: nagging/punishment/e.g. gloves, mittens or arm splints in thumb sucking,

3. Special councelling for grown up children who can understand.

4. Mentoring: To maintain self-esteem.

5. Research: It is important have our own study and data. 


\section{Bibliography:}

1. CPL Freeman (1998). Neurotic disorders. Companion to Psychiatric Studies, p. 475 (Childhood behaviors and adult neurosis).

2. Stevens Marans, Donald J. Coner (2002). Child Psychoanalytic theories of development. Child and adolescent Psychiatry, $3^{\text {rd }}$ ed. P. 195-211.

3. M Papakumari (1992). Child Psychiatry. PG Psychiatry.

4. Robert S. Feldman 91996). Personality. Understanding Psychology, $4^{\text {th }}$ ed. P. 475.

5. Elizabeth B. Hurlock (1993). Personality pattern. Personality development.

6. Elizabeth B. Hurlock (1997). Personality development. Child development, $6^{\text {th }}$ ed. P. 525-528.
7. Goodwin RD, Fergusson DM, Herwood LJ (2003). Neuroticism in adolescence and psychotic symptoms in adulthood. Psychology Med. 2003. 33 (6): 1089-97.

8. Kitamura T Fusihara (2003). Understanding Personality traits from early life experiences. Psychiatry clinic. Neuroscience 57(3) 823-32.

9. Furukawa O, Hai S, Yoshida S, et al (1998). Pre-morbid personality traits of patients with organic (ICD - 10, F0), schizophrenic (F2), mood (F3) and neurotic disorders (F4) according to $5 \mathrm{f}$ model of personality.

10. Morgan, King et al (1993). Personality. Introduction to Psychology, p. 566-609.

11. John Murtagh. Patient Education, $2^{\text {nd }}$ edition. MCGraw Hill Book Company. 